\title{
The Benefits of, and Barriers to, Implementation of 5D BIM for Quantity Surveying in New Zealand
}

Ryan Stanley and Derek Thurnell, (Unitec Institute of Technology, New Zealand)

\begin{abstract}
Building Information Modelling (BIM) models are relational and parametric in nature, and 5D BIM is where model objects include specification data and other properties which can be directly used for pricing construction work. There is huge potential for its use by quantity surveyors (QSs) for such tasks as quantity take-offs, estimation and cost management, in a collaborative project environment. Perceptions regarding the benefits of, and barriers to, the implementation of 5D BIM by quantity surveyors in Auckland are presented, based on structured interviews with 8 QSs. Results suggest that 5D BIM may provide advantages over traditional forms of quantity surveying in Auckland by increasing efficiency, improving visualization of construction details, and earlier risk identification. However there are perceived barriers to 5D BIM implementation within the construction industry: a lack of software compatibility; prohibitive set-up costs; a lack of protocols for coding objects within building information models; lack of an electronic standard for coding BIM software, and the lack of integrated models, which are an essential pre-requisite for full inter-operability, and hence collaborative working, in the industry. Further research is recommended, to find solutions to overcome these barriers to inter-operability between 3D and 5D BIM, in order to facilitate the cost modelling process.
\end{abstract}

Keywords: BIM, Estimating, Inter-operability, Quantity surveying

\section{Introduction}

Building information modelling [or management] (BIM) is a digital representation of a building's geometric and non-geometric data, and is used as a reliable, shared knowledge resource to make decisions on a facility throughout its lifecycle (NBIMS 2010).

BIM has been in use internationally for several years, and its use continues to grow. A survey covering BIM adoption rates across North America found that $67 \%$ of engineers, $70 \%$ of architects, and 74\% of contractors used BIM (McGraw-Hill Construction 2012). In the UK, the National BIM Report found that only 39\% of survey respondents in 2012 were both aware of, and actually using, BIM (National BIM Survey 2013). In Australia, a survey found that $49 \%$ of architects, and $75 \%$ of both engineers and contractors used BIM, and on average, that BIM is used on $36 \%$ (engineers) to $59 \%$ (architects) of projects (BEIIC 2010). New Zealand's only national BIM survey recently found that the proportion of BIM users increased from $34 \%$ [2012] to $57 \%$ [2013], with a year-on-year increase in overall BIM awareness in the construction industry, from $88 \%$ [2012] to $98 \%$ [2013] (Masterspec 2012; 2013).

BIM extends its use to incorporate a $4^{\text {th }}$ dimension (4D), 'time' and a 5 th dimension (5D), 'cost,' which specifically concerns the quantification, modification and extraction of data contained within the model in order to become the primary source of information for quantity surveying (QS) services. This research focuses on the cost dimension of BIM (5D BIM), and aims to present a "snapshot" of Auckland QSs' perceptions on the benefits of, and barriers to, the implementation of 5D BIM for quantity surveying. 


\section{D BIM}

5D BIM contains objects and assemblies in the BIM model that have a cost dimension added to them, either by incorporating cost data within the BIM model objects themselves, or which can be "live linked" to estimating software tools, which is current practice in New Zealand (Boon \& Prigg 2012). Parametric modelling then, facilitates the creation of a relationship between elements, and includes the specification and properties of individual elements and objects, [potentially] enabling the extraction of comprehensive and accurate information from the model which can be directly used for costing (Eastman et al. 2011). However, progress in the take up of 5D BIM is slow; in the UK, a recent survey of BIM users found that only $14 \%$ thought that BIM makes traditional bills [schedules in NZ] of quantities (BOQs) redundant (National BIM Survey 2013).

\section{BIM and 5D in New Zealand}

The use of 5D BIM in New Zealand (NZ) private quantity surveying (PQS) practices, whilst not as advanced as internationally, is developing; current use of 5D BIM for cost modelling is somewhat limited, and is restricted to certain specific aspects of cost modelling such as quantity take-offs for cost planning purposes (Stanley and Thurnell 2013). The only nationwide NZ survey found that only $8 \%$ of respondents sometimes automatically generate BOQs from their CAD models (although this may be explained, in part, by the fact that most respondents were from architectural or engineering design practices, rather than QSs). Furthermore, only $7 \%$ agreed that BIM makes traditional BOQs redundant within their organization (interestingly, far more [35\%] non-BIM users agreed) (Masterspec 2013).

This limited use of 5D BIM to date is perhaps due in part to lack of use of a single BIM model in NZ; instead, projects often utilise up to three different (and separate) models, which can encompass architectural, structural and services design documentation (Boon \& Prigg 2012). New Zealand's level of performance of BIM is basic, and most of the industry is still at Stage 1B ('Intelligent 3D') of the Australian Institute of Architects' (2009) BIM implementation scale. There is some anecdotal evidence that a few NZ construction projects are operating at Stage 2A: 'One-way Collaboration', where the (single) BIM model can be shared with other project participants for visualisation, coordination, communication, assessment, analysis, simulation or discipline design; however, the original model is updated in digital isolation from other discipline models (Australian Institute of Architects 2009).

Overseas studies have considered the benefits and barriers of BIM, in which estimators have been included (e.g. Sattineni \& Bradford 2011; Won, Lee \& Lee 2011). BIM will purportedly provide opportunities for the QS and clients by streamlining workflows and increasing the quality of cost services (Boon \& Prigg 2012); however, the barriers must be understood before the potential of $5 \mathrm{D}$ BIM can be reached. Literature pertaining to BIM and particularly 5D BIM in NZ is limited, and so this research aims to provide a "snapshot" of Auckland QSs' perceptions on the benefits of, and barriers to, the implementation of 5D BIM.

\section{Research Methods}

\section{Data Collection}

A cross-sectional survey approach was adopted, conducted over a small time frame, which was considered appropriate, as technology tends to change quickly. The sample population were quantity surveyors, whether in private practice, or working for a contractor. Purposive, non-probabilistic sampling ensured that only those people that had some BIM experience were selected. All responses were kept confidential, and participants' anonymity was ensured. Ethics approval was sought and obtained from Unitec's Ethics Committee.

Face to face interviews gave participants the opportunity to have the wording of questions clarified, and the interviewer the ability to ensure that the questions were interpreted as intended. In order to minimise the potential for introduction of interviewer bias, the interview

Stanley, R and Thurnell, D (2014) 'The benefits of, and barriers to, implementation of 5D BIM for quantity surveying in New Zealand', Australasian Journal of Construction Economics and Building, 14 (1) 105-117 
structure and questionnaire were piloted beforehand. The interviews were recorded which enabled post-hoc analysis of qualitative responses, in order to further reduce bias. Though a structured interview format was used, it also allowed for open ended, as well as closed questions. The format allowed the respondent to elaborate when needed, though also answer questions that were more targeted and closed, by using a semantic rating scale to assess the respondent's attitude towards the benefits of, and barriers to, implementation of 5D BIM.

\section{Questionnaire Design}

Section 1 was made up of closed questions which requested demographic information such as the number of employees in the participant's company, their role in the company, and the participant's experience with 5D BIM. No questions were mandatory; that is, there were no forced responses. Section 2 comprised 2 closed questions where respondents were asked to rate statements relating to the benefits and barriers of $5 \mathrm{D}$ BIM using a 5 point Likert-type semantic scale where: $1=$ Strongly Disagree, to $5=$ Strongly Agree. The items were drawn from a wide variety of sources in the literature (e.g. Popov et al. 2008; Boon 2009; Matipa, Cunningham \& Naik 2010; Olatunji, Sher \& Ogunsemi 2010; Samphaongoen 2010; Shen \& Issa 2010; Bylund and Magnusson 2011; Sattineni and Bradford II 2011; Boon \& Prigg 2012). Demographic information collected from respondents included: job role; years of QS experience; number of BIM projects worked on, and number of 5D BIM projects worked on.

\section{Data Analysis}

Participants' ratings of the benefits and barriers were analysed by identifying any general themes, if any, from the respondents' ratings. Responses to the subjective open ended questions were analysed by identifying the themes from the participant's responses and trends were identified.

\section{Findings}

\section{Demographic Information}

The demographic data collected from the eight participants is shown below in Table 1.

\begin{tabular}{|c|l|c|c|c|}
\hline Participant & \multicolumn{1}{|c|}{ Job/Position } & $\begin{array}{c}\text { Years } \\
\text { Experience }\end{array}$ & $\begin{array}{c}\text { Number of BIM } \\
\text { Projects }\end{array}$ & $\begin{array}{c}\text { Number of 5D } \\
\text { Projects }\end{array}$ \\
\hline A & PQS $^{*}$ & 35 & 0 & 0 \\
\hline B & Cntr QS $^{* *}$ (Director) & 15 & $1-2$ & 0 \\
\hline C & Cntr QS & 5 & 10 & $1-2$ \\
\hline D & Cntr QS (Director) & $30+$ & $1-2$ & 0 \\
\hline E & PQS (Director) & 25 & $1-2$ & 0 \\
\hline F & PQS & 3 & 0 & 0 \\
\hline G & Cntr QS (Director) & 18 & $3-4$ & $1-2$ \\
\hline H & PQS (Director) & 24 & $1-2$ & 0 \\
\hline
\end{tabular}

Table 1 Demographic Characteristics of Sample $(n=8)$

*PQS: private practice QS; **Cntr QS: contractor's QS

Four participants were from private practice, and 4 from contracting firms, and had a variety of quantity surveying experience and seniority, as well as experience with projects using BIM models, wherever possible.

\section{Benefits of 5D BIM}

Participants' level of agreement ( $1=$ Strongly Disagree, to $5=$ Strongly Agree) with statements relating to their perceptions regarding the benefits of 5D BIM implementation for quantity surveying in New Zealand are shown in Table 2, and the findings discussed below. 


\section{Q\#6.1: Visualization}

Visualization was seen as beneficial to QSs; this is consistent with Samphaongoen (2010), who describes QSs as being better able to understand the project they are involved in, as they can see and interact with the 3D model. Similarly, Thurairajah and Goucher (2013) assert that the building can be viewed from any perspective in $3 \mathrm{D}$, allowing QSs to make fewer assumptions about the design. As one participant stated: 'As opposed to turning over three or four hundred $A 2$ or $A 12 D$ drawings to try and get a picture of what the building looks like, the $3 D$ model gives you that instantaneously.'

\section{Q\#6.2: Collaboration}

5D BIM was perceived to enhance collaboration on projects, as people need to work together to make the models effective. This aligns with Popov et al. (2008) who assert that the use of 5D for cost modelling encourages collaboration on projects, and as such aids the management of the project overall. In order to achieve effective 5D, designers need to generate suitable 3D information, and this needs to be checked for clashes by the construction team. 5D software also has the ability to check for clash detection, and in this way a collaborative atmosphere is further encouraged (Won et al. 2011).

BIM depends on a collaborative approach, ideally through the use of a centralized model, where design changes are automatically updated and coordinated amongst the project team (although this is rarely achieved to date). Eastman et al (2011) assert that collaboration can be achieved by two different approaches: the first is where project teams utilize one model software from one vendor that contains all relevant design and cost information. The second approach is where project teams use proprietary or open-source software from different vendors, that contain mechanisms to ensure that data is fully exchangeable. As the software can be utilized across different disciplines, the model can be transferred between for example, QSs, architects, buildings services engineers and other consultants. This allows for real time changes to be suggested and made electronically during construction (ArandaMena et al 2008).

\begin{tabular}{|c|c|c|c|c|c|c|}
\hline Q\# & Benefits & 1 & 2 & 3 & 4 & 5 \\
\hline 6.1 & $\begin{array}{l}\text { The visualization of projects is increased e.g. construction } \\
\text { details. }\end{array}$ & & & & 4 & 4 \\
\hline 6.2 & $\begin{array}{l}\text { Collaboration on projects is enhanced as people need to work } \\
\text { together to make the models effective. }\end{array}$ & & & 2 & 6 & \\
\hline 6.3 & $\begin{array}{l}\text { The quality level of the finished projects is improved as the } \\
\text { quality of data in BIM models is maintained by its users. }\end{array}$ & 1 & & 4 & 2 & 1 \\
\hline 6.4 & $\begin{array}{l}\text { Project conceptualization is made easier e.g. 3D facilitates the } \\
\text { costing of design options during early design stage. }\end{array}$ & & 1 & 2 & 2 & 3 \\
\hline 6.5 & $\begin{array}{l}\text { Increased ability to print out design details from 5D software } \\
\text { enables greater analysis capability. }\end{array}$ & 1 & 1 & 4 & 1 & 1 \\
\hline 6.6 & $\begin{array}{l}\text { 5D offers more efficient take-offs during the Budget Estimate } \\
\text { Stage (i.e. } \$ / m 2 \text { GFA). }\end{array}$ & & & 4 & 2 & 2 \\
\hline 6.7 & $\begin{array}{l}\text { 5D offers more efficient generation of quantities for cost } \\
\text { planning compared to traditional QS software and manual take } \\
\text { off during the Detailed Cost Plan Stage (i.e. sub-elemental). }\end{array}$ & & & 4 & 2 & 2 \\
\hline 6.8 & $\begin{array}{l}\text { Earlier risk identification e.g. potential clash detection is } \\
\text { improved, at an earlier stage than with traditional approaches. }\end{array}$ & & 1 & & 2 & 5 \\
\hline 6.9 & Increased ability to resolve RFl's in real time. & & 1 & 2 & 3 & 2 \\
\hline 6.10 & $\begin{array}{l}\text { Estimating is improved through the ability to model project } \\
\text { options before and during construction. }\end{array}$ & & 1 & 2 & 2 & 3 \\
\hline
\end{tabular}

Table 2 Statements Relating to the Benefits of 5D BIM for Quantity Surveying ( $n=8)$

Stanley, R and Thurnell, D (2014) 'The benefits of, and barriers to, implementation of 5D BIM for quantity surveying in New Zealand', Australasian Journal of Construction Economics and Building, 14 (1) 105-117 


\section{Q\#6.3: Project Quality and BIM Data Quality}

The quality level of the finished projects is perceived to be improved, as the quality of data in BIM models is maintained by its users. One participant (with extensive experience on projects with BIM, and also some use of 5D BIM) strongly disagreed that BIM improves data quality: 'Sometimes the quality of the data in BIM models is much reduced. A lot of objects don't have any relevant information for a QS to use.' This highlights an issue which relates to a lack of uniformity in the way models are built, and the information they contain. The reliability of BIM estimates is dependent on the accuracy and completeness of the BIM model, which is often simplified, with minimal construction or assembly information. Standardization issues, such as when descriptions for 3D objects and the same objects in $5 \mathrm{D}$ software don't match is one of the reasons why QSs are not using BIM for the production and pricing of BOQs (Boon 2009).

\section{Q\#6.4: Project Conceptualization}

Project conceptualization is perceived to be made easier with BIM, e.g. 3D facilitates the costing of design options during the early design stage. This is consistent with Popov et al (2008), who describe BIM as providing the ability to check each part of the project in relation to each of the project's options. BIM enables QS involvement in the design at an earlier stage than on traditional projects, allowing the design team to produce more design options, which enables the QS 'to quickly and efficiently produce advice to the design team and client of the cost of each option in a manner that enables direct comparison to be made' (Boon \& Prigg 2012, p.7). Two participants agreed with the ability of BIM to be used at the design stage to influence the project, with one suggesting that it aids in obtaining acceptance from the client, as they are able to see the design early. Boon (2009) echoes this, saying that BIM is used at the tendering stage of projects for showing customers footage of the construction process.

\section{Q\#6.5: Analysis Capability}

Opinion on the ability of BIM to print out design details from 5D software to enable greater analysis capability was split; this may highlight a difference of opinion between the 5D concept and the reality of 5D at present. Due to the nature of the information contained in 5D models, it is possible to use the model to print out design details, and to generate reports that are useful to other members of the project team, i.e. design changes to be made by architects, and changes to the construction program (Popov et al. 2008)., although it may be that some people are yet to determine the usefulness of BIM for data analysis in its current state.

\section{Q\#6.6: Efficiency of Take-offs during Budget Estimate Stage}

None of the participants disagreed that BIM improves the efficiency of take-offs during Budget Estimate stage (i.e. \$/m2 GFA), which suggests some perceived benefits for QSs with BIM during the Budget Estimate stage. The extraction of quantities for preliminary budget estimating is relatively simple, but it is critical that the QS identifies items missing from the model at the time of extraction (Boon and Prigg 2012). 5D BIM can provide a high level of cost detail which can be useful in the early design stages, and certain software providers are now making it possible to develop detailed cost plans by live linking the model to a 5D cost library (Thurairajah \& Goucher 2013).

\section{Q\#6.7: Efficiency of Cost Planning during Detailed Cost Plan Stage}

No participants disagreed that 5D BIM offers more efficient generation of quantities for cost planning compared to traditional QS software and manual take off during the Detailed Cost Plan Stage (i.e. sub-elemental level). One participant stated 'You can do a whole complete building harvest just by pushing a button. You can get the quantities any way you want it basically.' Another stated 'An external wall that might have taken a good couple of hours to measure could be measured in about three mouse clicks'. Despite this, participants also noted that extensive bulk checking is required to ensure the quantities are correct, which in

Stanley, R and Thurnell, D (2014) 'The benefits of, and barriers to, implementation of 5D BIM for quantity surveying in New Zealand', Australasian Journal of Construction Economics and Building, 14 (1) 105-117 
turn reduces the efficiency gained: 'a lot of traditional bulk checking still needs to be done'. Although the ability to automatically extract quantities from the BIM model reduces the time required to generate cost plans, the extraction of quantities is extremely complex due to the model containing unreliable information and an expert is often required to operate the resource (Monteriro and Martins 2013).

A quantitative study found that even when detailed estimates are produced by relatively inexperienced estimators, 5D was more effective than that of the traditional 2D estimating methods, especially with a reduction in errors and time taken (Shen and Issa 2010). This provides a further benefit, as based on these findings it is thought that firms with intermediate level staff (relatively early on in their careers) are able to be efficient at cost planning when using 5D as opposed to 2D. Moreover, where parts of a QSs role require a lot of time to process the work, BIM is able to process vast amounts of data relatively quickly and has the potential to make work easier (Samphaongoen 2010).

5D BIM costing applications are theoretically contained in the model itself, using integrated cost databases embedded within 5D models, helping to streamline the work of QSs, as rather than relying on data storage external to the application they are using for costing projects, the data is able to be applied to projects and updated as required by importing up to date information. When required, the data can be used to cost the items measured from within the one piece of software. One of the benefits of these integrated cost databases is that all relevant information is stored in one location (Samphaongoen 2010). However, instead, in practice, "live linking" models to estimating platforms is done (Thurairajah \& Goucher 2013). This also seems to be the case in New Zealand at present (Boon \& Prigg, 2012; Stanley \& Thurnell 2013).

\section{Q\#6.8: Risk Identification}

Seven of 8 participants agreed that BIM offers earlier risk identification e.g. potential clash detection is improved at an earlier stage than with traditional approaches. These findings seem consistent with a study in Korea where it was found that clash detection was used in over $70 \%$ of projects (Won et al 2011). This indicates a clear link between BIM and the ability to reduce risk on projects.

The importance of identifying risks early on in projects is thought to be a vital element to a project's success. One participant supported this 'Clash detection is key for us, everything relates to time.' This echoes Thurairajah and Goucher (2013), who state that clash detection is a key benefit of BIM for cost consultants. The use of BIM to reduce risk is supported by Boon (2009) where QSs are able to analyze risk earlier and derive other construction options. By finding problems early, it may be possible to save both time and money.

\section{Q\#6.9: Ability to Resolve Requests for Information (RFIs) in Real Time}

Five of 8 participants agreed that BIM enables the increased ability to resolve RFl's in real time. This suggests that some projects in Auckland are able to use BIM during the construction phase, and not just during the design phase for visualization purposes. This is supported by Ghanem and Wilson (2011) who discuss a case study on a project which demonstrated that by using BIM they were able to save money by detecting clashes and therefore avoid RFIs.

\section{Q\#6.10: Estimating and Project Options}

Only 1 participant disagreed with the notion that estimating is improved through the ability to model project options before and during construction. By considering project options early, fewer variations are likely to occur during construction. One participant described how when considering different project options in 5D, 'You can see the quantities change and can update based on that.' The ability to update and change quantities quickly can be a major benefit for QSs in terms of cost modelling. Another commented: 'If an architect does a new

Stanley, R and Thurnell, D (2014) 'The benefits of, and barriers to, implementation of 5D BIM for quantity surveying in New Zealand', Australasian Journal of Construction Economics and Building, 14 (1) 105-117 
model every week and you've got it linked up with a cost plan you can actually have the dynamic link so that it updates your quantities with the new model.'

Olatunji et al (2010) suggest that BIM allows professional QSs to identify factors that have economic benefit or consequence on various design options in order to select the most suitable and cost efficient proposal. Furthermore, early design advice 'should lead to increased client satisfaction as they are receiving earlier economic feedback on the alternatives available' (Thurairajah \& Goucher 2013, p.3).

\section{Barriers to 5D BIM Implementation}

Participants' level of agreement ( $1=$ Strongly Disagree to $5=$ Strongly Agree) with statements relating to their perceptions regarding the barriers to $5 \mathrm{D}$ BIM implementation for quantity surveying in New Zealand are shown below in Table 3, and the findings are then discussed.

\begin{tabular}{|c|c|c|c|c|c|c|}
\hline Q.\# & Barriers & 1 & 2 & 3 & 4 & 5 \\
\hline 7.1 & Lack of software compatibility restricts its use. & & & 2 & 3 & 3 \\
\hline 7.2 & $\begin{array}{l}\text { The setup cost inhibits its use i.e. software, training and } \\
\text { hardware costs. }\end{array}$ & & & 2 & 4 & 2 \\
\hline 7.3 & $\begin{array}{l}\text { Increased risk exposure discourages companies e.g. legal } \\
\text { issues such as ownership of BIM models. }\end{array}$ & & 2 & 3 & 2 & 1 \\
\hline 7.4 & Cultural resistance in companies hinders its effectiveness. & & 2 & 2 & 1 & 3 \\
\hline 7.5 & $\begin{array}{l}\text { Incompatibility with industry recognized element formats for cost } \\
\text { planning prevents companies from adopting the software (e.g. } \\
\text { the NZIQS "Elemental Analysis of Costs of Building Projects"). }\end{array}$ & 1 & 3 & 1 & 3 & \\
\hline 7.6 & $\begin{array}{l}\text { Incompatibility with current Standard Methods of Measurement } \\
\text { (i.e. "NZS } 4202: 1995 \text { "), prevents firms from adopting the } \\
\text { software for SOQ production. }\end{array}$ & 1 & 1 & 3 & 1 & 2 \\
\hline 7.7 & $\begin{array}{l}\text { Lack of integration in the model decreases the reliability and } \\
\text { effectiveness of } 5 \mathrm{D} \text { (e.g. Arch./Eng./MEP designers are not all } \\
\text { working off the same model). }\end{array}$ & & 1 & 1 & 3 & 3 \\
\hline 7.8 & $\begin{array}{l}\text { Lack of protocols for coding objects within BIM models by } \\
\text { designers hinder the development of cost modelling using BIM } \\
\text { (e.g. lack of complete specification information in BIM models } \\
\text { inhibits accurate quantity generation for estimating). }\end{array}$ & & & 2 & 2 & 4 \\
\hline 7.9 & $\begin{array}{l}\text { Some companies feel their current software meets their needs, } \\
\text { so see no need to change. }\end{array}$ & & 1 & 3 & 3 & 1 \\
\hline 7.10 & $\begin{array}{l}\text { The fragmented nature of the construction industry limits the } \\
\text { potential of BIM. }\end{array}$ & 1 & 1 & 1 & 4 & 1 \\
\hline 7.11 & $\begin{array}{l}\text { Lack of an electronic standard for coding BIM software to } \\
\text { Standard Methods of Measurement limits the potential of BIM } \\
\text { for cost modelling. }\end{array}$ & & & 2 & 2 & 4 \\
\hline
\end{tabular}

Table 3 Statements Relating to Potential Barriers to 5D Implementation $(n=8)$

\section{Q\#7.1: Software Compatibility}

No participants disagreed with the notion that a lack of software compatibility restricts the use of BIM, which may indicate that lack of inter-operability is a barrier to the use of 5D BIM for quantity surveying. One participant commented 'It's not about physical compatibility of the software, it's about the knowledge about working with different software.' Another commented 'If a lead architect is using Archicad and everybody else is using Revit there's still that gap which makes it very difficult for estimating in 5D.'

Inter-operability is the smooth exchange of information across all BIM disciplines involved which is required to maximize the benefits that BIM offers (Thurairajah \& Goucher 2013). 
However, fuelled by the fragmented and isolated construction industry, vendors often run software in proprietary type formats that restrict the exchange of critical building data between multiple organisations, and such incompatibility between the BIM model and estimating platforms is seen as a major barrier to 5D BIM implementation (Olatunji 2011). In an attempt to overcome this challenge, advancement is being made to improve the interoperability of data exchange between BIM models and costing tools through open data standards such as Industry Foundation Classes (IFCs). IFC standards have been generated by the International Alliance of Interoperability (IAI) to help govern the exchange of data between CAD software tools, estimation software tools and other construction application software tools by creating a neutral file format. IFCs are believed to be important for cost consultants, as without complete inter-operability, items will be missed from the BIM model as they are combined, and therefore missed from estimates and schedules of quantities. However, there are still compatibility issues associated with IFC type files that industry is currently trying to work through (Thurairajah \& Goucher 2013

\section{Q\#7.2: 5D Setup Costs, i.e. Software, Training \& Hardware Costs}

Six of 8 participants agreed that the setup cost of 5D inhibits its use i.e. software, training and hardware costs. Software and hardware upgrades are considered as significant barriers to BIM implementation, particularly for small-medium enterprises (SMEs) (McGraw-Hill Construction 2012). One participant alluded to big companies being able to meet the setup costs, however for 'medium tier or smaller companies it's fairly expensive'. Thurairajah and Goucher (2013), in a survey of quantity surveyors about the benefits and barriers of 5D BIM implementation, found that most of the respondents indicated a strong training requirement associated with BIM implementation, which, although time-consuming and difficult (as only a number of users have expert knowledge in the resource), is considered critical to BIM's adoption.

\section{Q\#7.3: Risk Exposure}

There was only slight agreement overall that increased risk exposure discourages companies', e.g. legal issues such as ownership of BIM models, however 3 participants seemed undecided. The legal issues such as who has rights to the information contained in the BIM models, who is in charge of the information that is in the model, what happens when there are errors in the model and other responsibilities that relate to the model need to be addressed (Boon 2009). Klein (2012) concurs, and reports 'before the full potential of BIM can be released with parties working in collaboration, there needs to be an innovation in contracts and insurances that underwrites stakeholders for financial loss' (p.14).

\section{Q\#7.4: Cultural Resistance}

Only 2 of 8 participants disagreed with the notion that cultural resistance in companies hinders BIMs effectiveness for cost modelling. Participants made reference to the traditional nature of the industry, one surmising 'We're basically going from horse drawn carts to motor vehicles.'

A recent case study in New Zealand related how several BIM-capable project participants were not prepared to share BIM information between firms (Brewer, Gajendran \& Runeson 2013). This type of culture or dynamic on projects may pose another barrier to successful BIM adoption and use for 5D BIM by QSs, and cultural transformation is a much greater challenge than any technological challenge arising from BIM; there is some reluctance from older QS employees to use 5D BIM, but younger employees are much more optimistic (Boon \& Prigg 2012).

\section{Q\#7.5 Incompatibility with Industry Recognized Cost Planning Element Formats}

Only 3 participants agreed with the notion of 5D BIM's incompatibility with the industry recognized elemental format for cost planning, which prevents companies from adopting the software (e.g. the NZIQS 'Elemental Analysis of Costs of Building Projects'). Shen and Issa

Stanley, R and Thurnell, D (2014) 'The benefits of, and barriers to, implementation of 5D BIM for quantity surveying in New Zealand', Australasian Journal of Construction Economics and Building, 14 (1) 105-117 
(2010) found that estimating using 3D software when contrasted with traditional 2D estimating resulted in reduced errors and time taken.

However, Boon and Prigg (2012) report that BIM models currently contain numerous design errors and often have important information missing from them, which hinders BIM's use for producing $5 \mathrm{D}$ cost services, as the data is too incomplete or inaccurate to use.

In order to provide cost planning services when using BIM, there is a need for BIM models to be correct, complete and objects must contain all the data needed, which at present is not the case in New Zealand. Furthermore, significant time is needed to pick up what is not shown in the models by reviewing $2 \mathrm{D}$ drawings that show the missing building items (Stanley \& Thurnell 2013).

\section{Q\#7.6: Incompatibility with Current Standard Methods of Measurement (SMM)}

There was a great deal of mixed opinion between the participants on this issue of BIM's incompatibility with current Standard Methods of Measurement (i.e. 'NZS 4202:1995'), preventing QS firms from adopting 5D software for BOQ production. One participant asserted that NZS 4202:1995 is incompatible with 5D, "except for about 5 trades, like Blockwork, Brickwork, Concrete and maybe Suspended Ceilings. However everything else are pretty much composite items.' This sentiment is common in the literature; Matipa et al (2010) suggest that current Standard Methods of Measurement were developed for more paper based surveying. In New Zealand, there is little use of 5D BIM to produce efficient BOQs; Stanley \& Thurnell (2013) report 'few participants agreed that there is currently an increased use of 5D BIM for the production and pricing of Schedules (Bills) of Quantities (SOQs) during tender/bid stage' (p. 5). However, Boon and Prigg (2012) assert that marginal benefits can be achieved through the extraction of certain building items such as doors, windows, volumes of concrete, steelwork quantities, and services trades.

\section{Q\#7.7: Lack of Integration in the Model}

Six of 8 participants agreed that a lack of integration in BIM models decreases the reliability and effectiveness of 5D (e.g. where each design discipline develops their own BIM model in isolation from each other). One participant said 'We find it's all time and cost related. Initial models we receive are poorly integrated with each other, we spend a lot of time making it integrated.' Boon and Prigg (2012) assert that a balance needs to be found between the information architects need to use to build the 3D models, and the additional information needed for QSs to model the costs in projects. This underlying issue - lack of integration, where parties in the industry are said to work separately, and as a result this also separates the information required for BIM - is thought to be a major barrier to 5D BIM implementation (Bylund \& Magnusson 2011).

\section{Q\#7.8: Lack of Protocols for Coding BIM Objects}

Six of 8 participants agreed that a lack of protocols for coding objects within BIM models by designers hinders the development of 5D BIM. The need for a coding standard for 5D was highlighted by one participant 'I think a standard is probably needed, no different to the measuring standard that we have, just so that it can be standardized throughout the industry.' The Royal Institution of Chartered Surveyors (RICS) in the UK have worked with industry to develop new rules of measurement (NRM) which will facilitate 5D BIM, and are extending this collaboration with the Australian Institute of Quantity Surveyors in Australia (buildingSMART 2012). Currently in New Zealand there are no standards that facilitate the embedment of design data to ensure extracted quantities are compliant with the quantity surveyor's SMM (e.g. NZS 4202:1995), but a technical sub-committee of the New Zealand Institute of Quantity Surveyors (NZIQS) is attempting something similar by proposing the use of the Association of Coordinated Building Information in New Zealand's (ACBINZ) Coordinated Building Information (CBI) classification system to revise New Zealand's standard method of measurement. The CBI classification system was created to coordinate information sources such as drawings, specifications, quantities, technical and research

Stanley, R and Thurnell, D (2014) 'The benefits of, and barriers to, implementation of 5D BIM for quantity surveying in New Zealand', Australasian Journal of Construction Economics and Building, 14 (1) 105-117 
information and publications (Masterspec, 2012). The NZIQS sub-committee came to their conclusion on the basis that it was a similar coding system to the one used in Singapore, the Construction Electronic Measurement Standard (CEMS), a classification system established for BIM measurement that is globally recognised as being successful (Boon \& Prigg 2012).

\section{Q\#7.9: Current Software Meets Needs}

Only one of 8 participants disagreed that some companies feel their current software meets their needs, so see no need for change. This may suggest that smaller QS firms perceive 5D not to be a viable option at present. This characteristic of smaller consultant firms is shown in a study of small-medium enterprises (SMEs) in the UK Institution of Structural Engineers, which found that $73 \%$ of respondents think that BIM implementation presents serious cost and commercial challenges, and $76 \%$ of small (less than 10 employees) firms are not BIMexperienced, and so have little understanding of the finer details (Office Insight 2013).

\section{Q\#7.10: Fragmented Nature of the Construction Industry}

Only 2 of 8 participants disagreed that the fragmented nature of the construction industry limits the potential of BIM. Masterspec (2012) sees this as one of the central barriers to BIM implementation, and suggests that a shift in current workflows is required. Olatunji et al. (2010) assert that BIM, and in particular 5D BIM, requires the collaboration, database integration and commitment of companies to the use of BIM software, and that as these areas are still in a separated and fragmented state, it further limits the effectiveness of 5D BIM.

\section{Q\#7.11: Lack of an Electronic Standard for Coding BIM Software}

There was a high level of agreement from participants that a lack of an electronic standard for coding BIM software to Standard Methods of Measurement limits the potential of 5D BIM. One participant indicated the need for an electronic standard for BIM by saying, 'Often the designers don't code everything and if they code it they can code it incorrectly. With software, to some extent it's only as good as the information that's input in the first instance.' Although BIM-assisted estimating tools can generate large quantities of construction items in order to efficiently produce cost estimates, the extracted quantities have a lack of understanding of construction methods and procedures, which reduces the accuracy of estimates (Shen \& Issa, 2010). It is these kinds of issues that a common electronic coding standard for BIM would need to address. The NZ Government's Productivity Partnership is working through the National Technical Standards Committee (NTSC) to produce an online BIM handbook for New Zealand, as part of its strategy to accelerate the application of BIM in construction here. NTSC has commissioned NATSPEC of Australia to write the New Zealand BIM handbook, currently due for release for industry comment, as well as electronic exchange standards (BIM Handbook in Production 2013).

\section{Conclusions}

The perceptions of a sample of Auckland quantity surveyors on the benefits of, and barriers to, the implementation of 5D BIM have been identified. Findings suggest that 5D-BIM may provide advantages over traditional forms of quantity surveying (in Auckland) by increasing efficiency, increasing visualization of construction details, and earlier risk identification. However there are perceived barriers to 5D-BIM implementation within the construction industry: a lack of software compatibility; prohibitive set-up costs; a lack of protocols for coding objects within building information models; lack of an electronic standard for coding BIM software, and the lack of integrated models, with objects containing full and complete data required to fulfil cost modelling tasks efficiently, which are an essential pre-requisite for full inter-operability, and hence collaborative working, in the industry. As currently practised, 5D BIM takes place outside the core BIM model by live linking it to a third party estimating software. Participants had doubts for the feasibility of level 3 full collaborative BIM that contains integrated cost data, suggesting that the ultimate goal of BIM may never eventuate.

Stanley, R and Thurnell, D (2014) 'The benefits of, and barriers to, implementation of 5D BIM for quantity surveying in New Zealand', Australasian Journal of Construction Economics and Building, 14 (1) 105-117 
However, there was a strong indication that 2D drawings would eventually succumb to BIM in the future.

Some participants noted that in the future, such barriers are likely to be overcome by increasing cross-disciplinary collaboration on BIM modelling, allowing 5D BIM use to become more prominent. It is thought that as the use of BIM increases, a cultural change will take place, and 5D BIM will increasingly be more widely used by quantity surveyors in the Auckland construction industry for cost modelling. Although (due to the small sample size) these findings are not generalizable to the New Zealand quantity surveying population as a whole, they do provide a 'snapshot' of current opinion on the benefits of, and barriers to, the implementation of 5D BIM in Auckland. The accelerating implementation of BIM means that these perceptions are likely to change in the future, and this research provides a benchmark against which to gauge changes in the use of 5D BIM for cost modelling, which could help find solutions to overcome these barriers to inter-operability between 3D and 5D BIM, and report on the opinions of industry to the solutions once they have been implemented.

\section{References}

Aranda-Mena, G., Crawford, J., Chevez, C., \& Froese, T. (2008) 'Building information modelling demystified: Does it make business to adopt BIM?' CIB W78 2008 International Conference on Information Technology in Construction, Santiago, Chile

Australian Institute of Architects (2009) 'Towards Integration. National Building Information Modelling (BIM) Guidelines and Case Studies', Cooperative Research Centre for Construction Innovation (CRCCl), viewed 11 May 2013 http://www.construction-innovation. info/images_/pdfs/Brochures/Towards Integration Brochure 170409b.pdf

BEIIC (2010) 'Productivity In The Buildings Network: Assessing The Impacts Of Building Information Models', Built Environment Innovation and Industry Council (BEIIC), Melbourne, Australia

BIM Handbook in Production (2013) Building \& Construction Productivity Partnership, viewed 29 November 2013 http://buildingvalue.co.nz/news-events/bim-handbook-production

Boon, J. (2009) 'Preparing for the BIM revolution', $13^{\text {th }}$ Pacific Association of Quantity Surveyors Congress (PAQS 2009), viewed 12 April 2013 http://rismwiki. vms.my/images 17/72/PREPARING FOR THE BIM REVOLUTION.pdf

Boon, J., \& Prigg, C. (2012) 'Evolution of quantity surveying practice in the use of BIM - the New Zealand experience', Joint CIB International Symposium of W055, W065, W089, W118, TG76, TG78, TG81 and G84, viewed 5 July 2013 http://www.irbnet.de/daten/iconda/CIB DC25601.pdf

Brewer, G., Gajendran, T. \& Runeson, G. (2013) 'ICT \& innovation: A case of integration in a regional construction firm', Australasian Journal of Construction Economics and Building, 13 (3), 24-36

buildingSMART Australasia (2012) 'National Building Information Modelling Initiative', Vol.1, viewed 4 July 2013 http://buildingsmart.org.au/nbi-folder/NationalBIMlniativeReport 6June 2012.pdf

Bylund, C. \& Magnusson, A. (2011) 'Model based cost esimations-an international comparison', viewed 4 July 2013 http://www.bekon.lth.se/fileadmin/byggnadsekonomi/Carl Bylund AMagnusson Model Based Cost Estimations - An International Comparison $\underline{2 . \mathrm{pdf}}$

Eastman, C., Teicholz, P., Sacks, R. \& Liston, K. (2011) BIM Handbook: A Guide to Building Information Modeling for Owners, Managers, Designers, Engineers and Contractors, John Wiley and Sons, NY 
Ghanem, A. A. \& Wilson, N. (2011) 'Building information modelling applied on a major csu capital project: A success story', 47th ASC Annual International Conference, viewed 30 May 2013 http://ascpro0.ascweb.org/archives/cd/2011/paper/CPGT274002011.pdf

Klein, R. (2012) 'A work in progress', RICS Construction Journal, Feb-Mar 2012, 14

Masterspec. (2012) New Zealand National BIM Survey 2012, viewed 10 May 2013 http://ww w.masterspec.co.nz/news/reports-1243.htm

Masterspec. (2013) New Zealand National BIM Survey 2013, viewed 22 November 2013 http://www.masterspec.co.nz/news/reports-1243.htm

Matipa, W.M., Cunningham, P. and Naik, B. (2010) 'Assessing the impact of new rules of cost planning on building information model (BIM) schema pertinent to quantity surveying practice', 26th Annual ARCOM Conference, viewed 16 October 2013 http://web.itu.edu.tr/ чyamanhak/yayin/p2010b.pdf

McGraw-Hill Construction (2012) The Business value of BIM in North America: Multi-Year Trend Analysis and User Ratings (2007-2012), McGraw-Hill Construction, New York

Monteiro, A. \& Martins, J.P. (2013) 'A survey on modeling guidelines for quantity takeofforiented BIM-based design', Automation in Construction, 35, 238-253

National BIM Survey (2013) 'National BIM Report 2013', viewed 22 November 2013 http://www.thenbs.com/pdfs/NBS-NationIBIMReport2013-single.pdf

NBIMS (2010) 'National Building Information Modeling Standard', viewed 11 November 2013 http://www.wbdg.org/pdfs/NBIMSv1 p1.pdf

Office Insight (2013) 'Government unveils BIM initiative for SMEs as survey reveals small business concerns', viewed 29 November 2013 http://workplaceinsight.net/governmentunveils-bim-initiative-for-smes-as-survey-reveals-small-business-concerns/?goback=.gde 88902 member 274944403

Olatunji, O.A. (2011) 'Modelling organizations structural adjustment to BIM adoption: A pilot study on estimating organizations', Journal of Information Technology in Construction, 16, 653-668

Olatunji, O.A., Sher, W., Ogunsemi, D.R., (2010) 'The impact of building information modelling on construction cost estimation', W055 - Special Track 18th CIB World Building Congress, May 2010, Salford, UK

Popov, V., Migilinskas, D., Juocevicius, V. and Mikalauskas, S. (2008) 'Application of building information modelling and construction process simulation ensuring virtual project development concept in 5D environment', 25th International Symposium on Automation and Robotics in Construction, viewed 12 March 2013 http://www.iaarc.org/pub lications/fulltext/7 sec 090 Popov et al Application.pdf

Samphaongoen, P. (2010) 'A visual approach to construction cost estimating', viewed 17 October 2013 http://epublications.marquette.edu/theses open/28

Sattineni, A. \& Bradford II, R. H. (2011) 'Estimating with BIM: A survey of US construction companies', Proceedings of the 28th ISARC, viewed 12 March 2013 http://www.iaarc.org /publications/proceedings of the 28th isarc/estimating with bim a survey of us construction companies.html

Shen, Z. \& Issa, R.R.A. (2010) 'Quantitative evaluation of the BIM-assisted construction detailed cost estimates', Journal of Information Technology in Construction, 15, 234-257, viewed 12 March 2013 http://www.itcon.org/2010/18

Stanley, R. \& Thurnell, D. (2013) 'Current and anticipated future impacts of BIM on cost modelling in Auckland'. Proceedings of 38th AUBEA International Conference, Auckland, New Zealand, 20-22 Nov 2013 
Thurairajah, N. \& Goucher, D. (2013) 'Advantages and challenges of using BIM: A cost consultant's perspective', 49th ASC Annual International Conference, viewed 20 November 2013 http://ascpro.ascweb.org/chair/paper/CPRT114002013.pdf

Won, J., Lee, G., and Lee, C. (2011). Comparative analysis of BIM adoption in Korean construction industry and other countries. University, Seoul, Korea, viewed 22 October 2013 http://biis.yonsei.ac.kr/pdf/Comparative\%20analysis\%20of\%20BIM\%20adoption\%20in\%20 Korean\%20construction\%20industry\%20and\%20other\%20countries.pdf 